\title{
Modelling healthcare internal service supply chains for the analysis of medication delivery errors and amplification effects
}

\author{
Banafsheh Behzad ${ }^{1}$, Reinaldo J. Moraga ${ }^{2}$, Shi-Jie (Gary) Chen ${ }^{2}$ \\ ${ }^{1}$ University of Illinois at Urbana-Champaign (USA), ${ }^{2}$ Northern Illinois University (USA) \\ behzad1@illinois.edu; rmoraga@niu.edu; garychen@,niu.edu
}

Received May 2010

Accepted July 2011

\section{Abstract:}

Purpose: Healthcare is a universally used service that hugely affects economies and the quality of life. The research of service supply chains has found a significant role in the past decade. The main research goal of this paper is to model and simulate the internal service supply chains of a healthcare system to study the effects of different parameters on the outputs and capability measures of the processes. The specific objectives are to analyse medication delivery errors in a community hospital based on the results of the models and to explore the presence of bullwhip effect in the internal service supply chains of the hospital.

Design/methodology/approach: System dynamics which is an approach for understanding the behaviour of complex systems, used as a methodology to model two internal service supply chains of the hospital with a sub-model created to simulate medication delivery errors in the hospital. The models are validated using the actual data of the hospital and the results are analyzed based on experimental design techniques.

Findings: It is observed that the bullwhip effect may not occur in a hospital's internal service supply chains. Furthermore the paper points out the conditions for reducing the medication delivery error in a hospital. 
Research limitations/implications: Because of the community hospital's data availability the type of service supply chains modelled in this paper, are small service supply chains, representing only the tasks which are done inside the hospital. To better observe the bullwhip effect in healthcare service supply chains, the chains should be modelled more generally.

Originality/value: The original system dynamics modelling of the internal service supply chains of a community hospital, with a sub-model simulating the medication delivery error.

Keywords: service supply chains, healthcare services, medication delivery error, amplification effect, bullwhip effect

\section{Introduction}

In today's global market, competition is ever increasing and companies are widely adopting customer-focused strategies in integrated-system approaches. Competition is no longer one company against other companies, but one supply chain against other supply chains. Supply chain management is a mechanism that will allow companies to respond to these environmental changes. It has become one of the top priorities on the strategic agenda of industrial and service businesses. Service supply chains should be managed differently, because they have the following characteristics not found in manufacturing supply chains: intangibility, heterogeneity, simultaneous production and consumption, and perishability (Zeithaml et al., 2009).

Healthcare is an expensive, complex, universally used service that hugely affects economies and the quality of life (Berry \& Bendapudi, 2007). The U.S., for example, was projected to spend more than $\$ 2$ trillion (nearly $\$ 7,000$ per person) on healthcare in 2006 and still only $44 \%$ of a national sample of Americans were satisfied with the quality of U.S. healthcare (Berry \& Bendapudi, 2007). The healthcare industry in the U.S. accounts for 16 percent of GDP, whereas the European Union average is about 8\% (Baltacioglu et al., 2007). There are several reasons for the growth of the healthcare industry. The most important one is decreasing fertility rates and increasing life expectancy. Several challenges like the complexity of processes, the need for efficient utilization of resources, the need to 
control the workload of the healthcare employees, and the public pressure on healthcare institutions to control costs while increasing the quality of services are involved with the healthcare industry (Baltacioglu et al., 2007). All these challenges prove the importance of supply chain management in healthcare organizations.

Most of the discussions in literature focus on supply chain operations in the healthcare industry from a manufacturing viewpoint (Fineman \& Kapadia, 1978; Bier, 1995; Rivard-Royer et al., 2002), but there are few discussions about applying service supply chain management principles to healthcare organizations. Baltacioglu et al. (2007) proposed a general supply chain model for services, which includes some managerial activities to be performed for effective management of service supply chains. These activities are demand management, capacity and resources management, customer relationship management, supplier relationship management, order process management, and service performance management. The proposed model is implemented for the healthcare industry.

Medication delivery error is an important issue faced by healthcare systems or, more specifically, hospitals. Recently, medication errors have become so common in hospitals that the patients should expect to suffer at least one every day (Baker et al., 2002). In 2006, the Institute of Medicine estimated that medication-related errors harm approximately 1.5 million people in the U.S., costing the nation at least $\$ 3.5$ billion annually. To help with these challenges, improving service supply chain for medication delivery processes in a hospital is very important. The medication preparation is usually done in the pharmacy of the hospital and then delivered to different departments of the hospital. So, analyzing the process of preparing drugs in the pharmacy of the hospital and measuring medication errors and wastes and trying to minimize them would have an important role in reducing the medicationrelated errors.

Upstream amplification of inventory and demand in a supply chain has been a wellknown phenomenon to supply chain managers for several decades. This phenomenon is called bullwhip effect in which fluctuations in orders increase as one moves up the supply chain from retailers to wholesalers to manufacturers and to suppliers. The evidence of bullwhip effect was first found by Forrester (1961) and was then demonstrated by Sterman $(1989 a, 1989 b)$ based on the famous Beer Game, an experiment that includes a supply chain with four stages. Lee et al. (1997) suggested four root causes of amplification effects in inventory supply chains: demand signaling, batch ordering, price fluctuations and shortage gaming. 
Most of the research on amplification effects, or bullwhip effects, has focused on manufacturing (or inventory) supply chains (Akkermans \& Vos, 2003). Although the research of service supply chains has found a significant role with the increasing importance of service industry in recent decade, there are few studies on the amplification phenomenon in service supply chains. Anderson et al. (2005) studied the dynamic behavior of service supply chains in the presence of varying demand and information sharing. Their model presented the relationships between capacity, processing, backlog and service delays at each stage in the supply chain. They characterized the conditions under which a bullwhip effect can occur. They indicated that depending on the policies used to manage each stage the bullwhip effect may not occur in service supply chains.

This paper focuses on service supply chains in the area of healthcare services based on a case study from a community hospital $(\mathrm{CH})$. The main research goal of this paper is to model and simulate the internal service supply chains of a healthcare system to study the effects of different parameters on the outputs and capability measures of the processes. The specific objectives are:

- To create system dynamics models for the internal service supply chains in $\mathrm{CH}$.

- To analyze medication delivery errors in $\mathrm{CH}$ based on the results of the models.

- To explore the presence of bullwhip effect in the internal service supply chains of the hospital.

\section{System dynamics modelling}

System dynamics is an approach to understanding the behavior of complex systems over time. In this study, system dynamics is used to model two internal processes in $\mathrm{CH}$ : the pharmacy internal service supply chain (i.e., medication preparation procedure in the pharmacy) and the emergency room internal service supply chain (i.e., the patient treatment procedure in the emergency room). Only one medication type, intravenous (IV), is considered in this study. The reason that we focused on IV is that medication errors associated with the highest risk of harm are IV medication errors (Williams \& Maddox, 2005). IV medications are associated with 54\% of potential adverse drug events (ADEs) (Kaushal et al., 2001), 56\% of medication errors (Ross et al., 2000), and approximately $61 \%$ of the serious and life-threatening errors (Vanerveen, 2005). The modelling software used is Vensim, 
which is a visual modelling tool that allows conceptualizing, documenting, simulating, and analyzing system dynamics models.

\subsection{Pharmacy internal service supply chain model}

The pharmacy service supply chain model contains three main stages: Computer Order Entering (the IV orders received from the other departments are entered into computer), Order Sorting (the labels are printed and sorted), and Order Assembling (the IVs are assembled). Each stage contains three variables: capacity, processing rate, and backlog. Capacity in each stage represents the number of IVs that a pharmacy staff can process per period. Capacity is changed by turnaround rate. Turn around rate is the rate of changing positions of the employees in pharmacy. For example there may be a need for more people in the order entering stage, so the manager may ask a pharmacist who is working in the order sorting section to help with the order entering. Capacity adjustment time is the average nominal delay required to adjust the pharmacy staff. Target capacity is the desired number of pharmacy staff required in each stage. Backlogs present the number of orders in queue to be processed. Backlogs decrease as processing rate increases. The average service delay is the average nominal delay required to complete a backlogged order. Figure 1 shows the first two stages of the pharmacy model, which is built based on Anderson et al. (2005). The following are the variables used in the model:

- $\quad \mathrm{B}_{\mathrm{i}}(\mathrm{t})=$ stage $i$ backlog at time $t$. We assume that $B_{i}(t) \geq 0$ for $t \geq 0$.

- $\quad \mathrm{C}_{\mathrm{i}}(\mathrm{t})=$ stage $i$ capacity in job at time $t$. We assume that $C_{i}(t) \geq 0$ for $t \geq 0$. $C_{0}(t)$ equals end-customer demand at time $t$.

- $\quad \mathrm{P}_{\mathrm{i}}(\mathrm{t})=$ the processing rate at stage $i$ at time $t$.

- $\quad \mathrm{TC}_{\mathrm{i}}(\mathrm{t})=$ target capacity of stage $i$ at time $t$.

- $\operatorname{TR}_{\mathrm{i}}(\mathrm{t})=$ turn around rate of the employees in stage $i$ at time $t$.

- $\mu_{\mathrm{i}}=$ the average nominal delay required to adjust capacity at stage $i$. We will refer to $\mu_{i}$ as the capacity adjustment time. We assume that $\mu_{i}>0$.

- $\quad \lambda_{\mathrm{i}}=$ the average nominal delay required to complete a backlogged order at stage $i$. We will refer to $\lambda_{i}$ as the average service delay. We assume $\lambda_{i}>0$.

- $\alpha_{i, 1}=$ the relative weight of end-customer demand in the target capacity decision of stage $i$. We assume that $0 \leq \alpha_{i, 1} \leq 1$. 
- $\alpha_{i, i}=$ the relative weight of local demand of stage $i$ in the target capacity decision of the same stage. We assume that $0 \leq \alpha_{i, i} \leq 1$.

- $\quad \mathrm{D}=$ the average pharmacy's demand for IV.

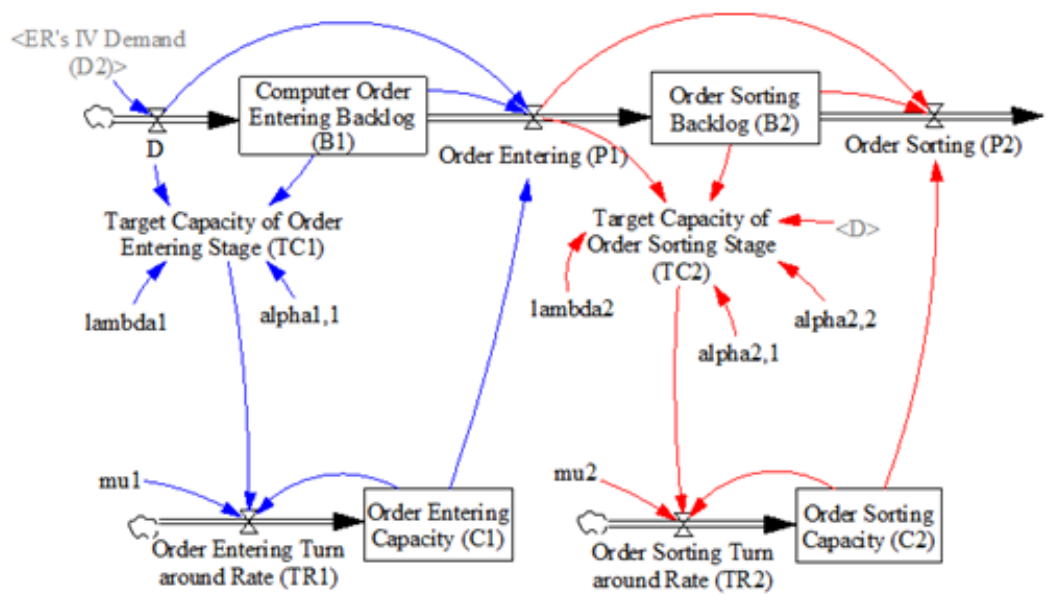

Figure 1. Pharmacy service supply chain model for the first two stages

The followings are the equations describe the model:

$$
\begin{aligned}
& \partial B_{i}(t) / \partial t=P_{i-1}(t)-P_{i}(t) \\
& \partial C_{i}(t) / \partial t=\left(\left(T C_{i}(t)-C_{i}(t)\right) / \mu_{i}\right)=T R_{i}(t) \\
& P_{i}(t)=I F\left(\left[\left(B_{i}(t)>0\right), C_{i}(t)\right], \text { Else }\left[\min \left(P_{i-1}(t), C_{i}(t)\right]\right)\right. \\
& \text { TC }(t)_{i}=\alpha_{i, 1} * C_{0}(t)+\alpha_{i, i} * P_{i-1}(t)+\left(1-\alpha_{i, 1}-\alpha_{i, i}\right) *\left(B_{i}(t) / \lambda_{i}\right)
\end{aligned}
$$

Equations 1 and 2 describe the rate of change of backlog and capacity at stage $i$ respectively. The rate of change of capacity at each stage is equal to the turnaround rate of that stage. According to equation 3, if stage $i$ backlog is positive, then production runs at full capacity. Otherwise, what is produced at stage $i$ equals production from the previous stage if this is less than stage $i$ capacity. In equation 4 , the first term represents the degree to which the target capacity relies on the end-customer demand rate. The second term captures the degree to which the target capacity depends on the processing rate of the previous stage. The third term denotes how the target capacity depends on the magnitude of the local backlog $B_{i}(t)$. The ratio in this term represents the capacity required to guarantee that, on average, the orders in each backlog will not be delayed longer than an acceptable amount of time (i.e., the average nominal delay). 


\subsection{Emergency room internal service supply chain model}

The emergency room service supply chain model contains four main stages: Patient Registration (by a registration clerk), Nurse Assessment, Doctor Diagnosis/Prescription, and Medication Preparation/Treatment (a nurse retrieves the required IV medications from the ER inventory room, prepares medications, and administers medications to the patient). Figure 2 shows the two first stages of the ER model. The patients demand (or patient's inter-arrival rate) is formulated as a random normal function based on the actual data of $\mathrm{CH}$. The logic of the ER model is similar to the logic of the pharmacy model.

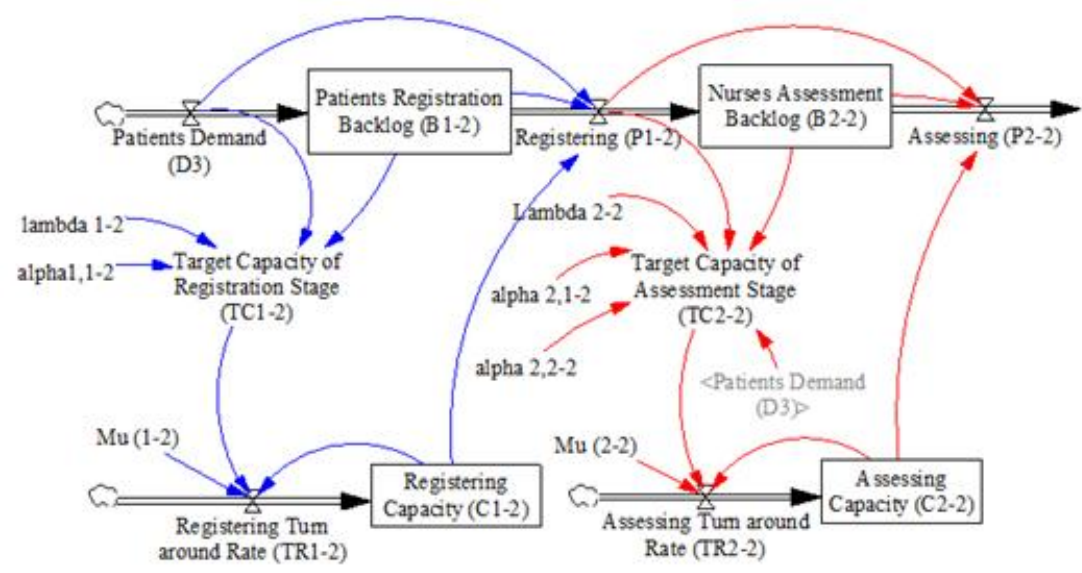

Figure 2. ER service supply chain model for the first two stages

\subsection{The linkage between the pharmacy and ER models}

Figure 3 shows a sub-model linking the pharmacy and ER models. ER's IV demand is sent to the pharmacy with a delay. The delay time contains two parts: one is the order delay related to the orders that reach the pharmacy by phone, fax, or computer; another is the waiting time delay that depends on how busy the pharmacy staffs are. The following are the variables used in this sub-model:

- D2: ER's IV Demand

- DT: Delay Time

- WD: Waiting Time Delay

- OD: Order Delay

- IV: IV's per Patient. Number of IVs which a patient will use during his stay in ER on average. This number is given using $\mathrm{CH}^{\prime}$ s real data. 
The followings are the equations describe the sub-model:

$$
\begin{aligned}
& \mathrm{D} 2=\mathrm{DELAY} \text { FIXED }\left(\mathrm{P}_{3-2} * \mathrm{IV}, \mathrm{DT}, \text { Initial }\right) \\
& \mathrm{DT}=\mathrm{OD}+\mathrm{WD} \\
& \mathrm{WD}=\mathrm{B}_{1} * \lambda_{1}
\end{aligned}
$$

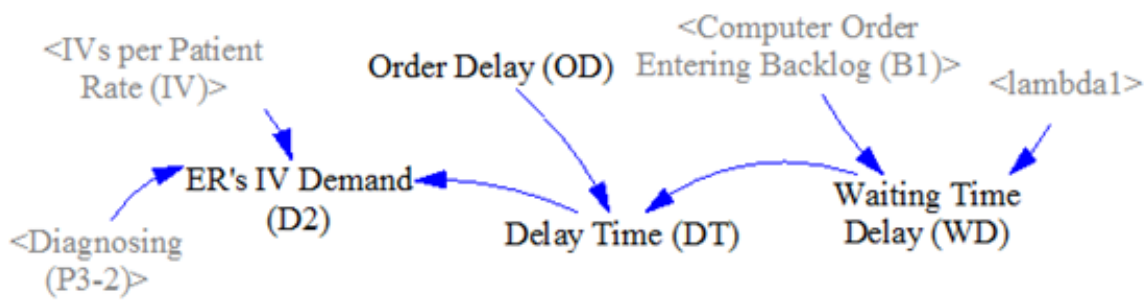

Figure 3. A Sub-model linking the pharmacy and ER models

Equation 5 states that, starting at time Initial, the amount of the IV's prescribed by the doctors will be delayed for a fixed amount of time DT. The delay time in equation 6 is the sum of the order delay and waiting time delay. Equation 7 defines the waiting time delay as the computer order entering backlog times the average service delay in the stage of computer order entering.

\subsection{Experience model}

The purpose of the experience model is to analyze the effect of experience on medication delivery errors. An experience model is built for each of the following positions: pharmacy staff, ER registration clerk, ER nurses and ER doctors.

Figure 4 shows the experience model for pharmacists as an example. The employee's average experience is calculated based on the average experience of new hires, hours worked per year, and fractional attrition rate. Fractional attrition rate is assumed constant but might vary with different organizational structure of the hospital. See Sterman (2000: page 506) for more information on fractional attrition rate. The following are the variable and inputs used in the experience model for ER doctors:

- Ex: Pharmacist's Average Experience

- AR: Pharmacist's Fractional Attrition Rate

- NEx: New Hired Pharmacist's Average Experience

- H: Pharmacist's Hours Worked per Year 
The following equation is used to define the pharmacist's average experience:

$$
E x=(A R * N E x+H) / A R
$$

Equation 8 describes that the pharmacist's average experience is a function of the hours worked per year and the average experience of the new hire, considering the fractional attrition rate. Pharmacist's Average Experience is used to calculate the medication delivery error. However the average experience and the reference experience level of other positions of the hospital (doctors, nurses and clerks) are calculated but not used in the rest of the model again.

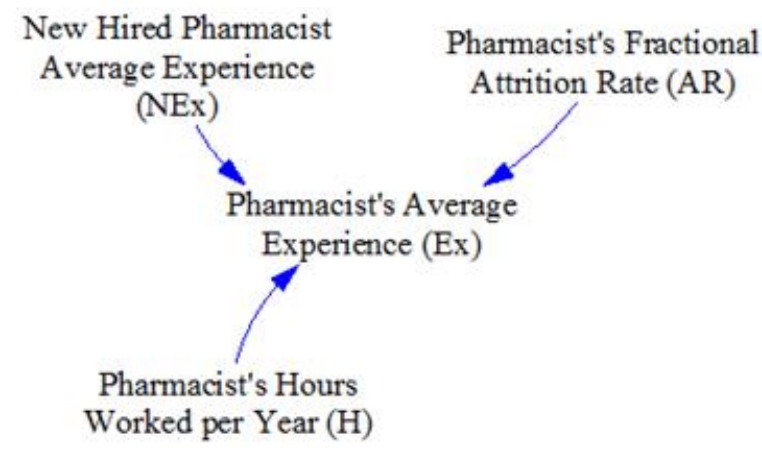

Figure 4. The Experience model for pharmacist

Figure 5 shows a sub-model of the pharmacy model, which simulates medication delivery error based on staff's workload and experience level.

The followings are the variables and input used in this sub-model:

- $\quad \mathrm{N}$ : Number of Pharmacists.

The capacities which we calculated before are actually the capacities in job. The number of pharmacists is calculated by separating the total pharmacists to two inexperienced and experienced groups. Using the productivity of each group which are given by the real data of the $\mathrm{CH}$, the total number of pharmacists is calculated.

- PhTC: Pharmacy's total capacity, which is the sum of order entering capacity, order sorting capacity and order assembling capacity.

- TB: Total backlog

- W: Total workload of the pharmacists

- EE: Total Effective Experience of all the pharmacists 
- MDE: Medication Delivery Error

- FP: Fractional Decrease in Error per Doubling the Experience

- FW: Fractional Increase in Error per Doubling the Workload (Zangwill \& Kantor, 1998)

- REx: Pharmacists Reference Experience Level. Is found using the $\mathrm{CH}^{\prime}$ 's real data.

- RE: Reference Error. A reference medication delivery error which is given by the $\mathrm{CH}$.

- RW: Reference Workload. A reference workload which is given by the $\mathrm{CH}^{\prime} \mathrm{s}$ real data.

- Per1: Pharmacists Inexperienced Percentage. This percentage is used to calculate the number of pharmacists and is given by the $\mathrm{CH}^{\prime}$ s real data.

- Pr1: Productivity of Inexperienced Pharmacists

- Pr2: Productivity of Experienced Pharmacists

The following are the formulas which describe the model:

$$
\begin{aligned}
& \mathrm{N}=(\mathrm{PhTC} * \text { Per } 1 / \mathrm{Pr} 1)+((\mathrm{PhTC} *(1-\mathrm{Per} 1)) / \mathrm{Pr} 2) \\
& \mathrm{W}=\mathrm{TB} / \mathrm{N} \\
& \mathrm{EE}=\mathrm{Ex} * \mathrm{TC} \\
& \text { Error }=\mathrm{RE} *((\mathrm{EE} / \mathrm{REx}) \wedge \mathrm{C} 1) *((\mathrm{~W} / \mathrm{RW}) \wedge \mathrm{C} 2) \\
& \text { Where } \mathrm{C} 1=\ln (1+\mathrm{fp}) / \ln (2), \mathrm{C} 2=\ln (1+\mathrm{fW}) / \ln (2)
\end{aligned}
$$

Equation 9 defines the number of pharmacists as a function of the productivity of the inexperienced and experienced pharmacists. The workload in equation 10 is the total backlog divided by the number of pharmacists. Equation 11 defines the total effective experience as the average experience times the capacity. In equation 12, the medication delivery error is equal to a function of the experience and workload. The constants $f p$ and $f w$ are fractional decrease in error per doubling the experience and fractional increase in error per doubling the workload, respectively. The fractional decrease in error $f p$ is negative because increasing experience will reduce 
error, while the fractional increase in error $f w$ is positive since higher workload increases error (Zangwill \& Kantor, 1998).

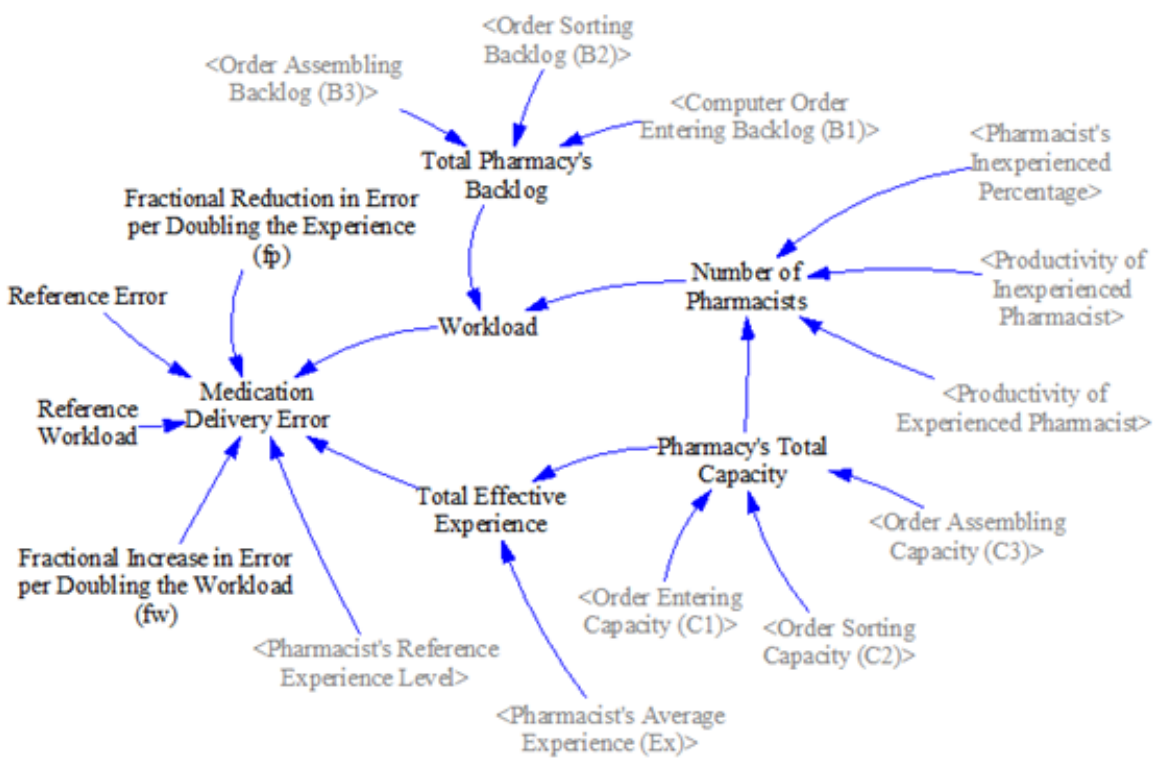

Figure 5. A Sub-model for medication delivery errors

\section{Model validation}

$\mathrm{CH}$ provided us the data of the medication delivery errors for 44 continuous weeks. Therefore, the model can be validated by comparing the medication delivery error values given by the simulation run and the real data from $\mathrm{CH}$. The unit time of entire model is hour. The model has been simulated for 500 hours and 44 medication delivery errors have been selected randomly from the simulation data. To be more precise about the error values given by the simulation run as well as to gain insights into the impact of the other parameters on medication delivery errors, an experimental design was employed. The experimental design consists of three parameters which have the most impact on the medication delivery error. Each parameter has two levels, which are shown in Table 1. In order to find how to change the current values of each parameter, many simulations were run, some trial and error experiments were performed, and the most appropriate new values for each parameter were chosen. The experimental design is done for three parameters: pharmacist reference experience level, reference error, and reference workload. By running some simulations it is found out that these parameters have the greatest impact on the medication delivery errors. The purpose of this experimental design is to find a set of values for these three parameters that result in a reasonable value for the medication delivery error to be as close as possible to the medication delivery error data of $\mathrm{CH}$. 


\begin{tabular}{|c|c|c|c|c|}
\hline \multicolumn{4}{|c|}{ Factor } & \multirow{6}{*}{$\begin{array}{c}\text { Mean } \\
\text { Square } \\
\text { Deviation }\end{array}$} \\
\hline $\begin{array}{l}\text { Factor } \\
\text { Level }\end{array}$ & $\begin{array}{c}\text { Pharmacist Reference } \\
\text { Experience Level (A) }\end{array}$ & $\begin{array}{l}\text { Reference } \\
\text { Error (B) }\end{array}$ & $\begin{array}{c}\text { Reference } \\
\text { Workload (C) }\end{array}$ & \\
\hline Units & Hour & IV/Hour & IV/Hour & \\
\hline Low & 4000 & 0.75 & 15 & \\
\hline High & 8000 & 1 & 30 & \\
\hline Run & Factor A & Factor B & Factor C & \\
\hline 1 & -1 & -1 & -1 & 0.175410 \\
\hline 2 & -1 & +1 & +1 & 0.162899 \\
\hline 3 & -1 & -1 & +1 & 0.180175 \\
\hline 4 & -1 & +1 & -1 & 0.166093 \\
\hline 5 & +1 & +1 & +1 & 0.164949 \\
\hline 6 & +1 & -1 & -1 & 0.172450 \\
\hline 7 & +1 & +1 & -1 & 0.169004 \\
\hline 8 & +1 & -1 & +1 & 0.176864 \\
\hline
\end{tabular}

Table 1. Values for the simulation model parameters which has impact on errors in the experimental design and experimental design formation and the mean square deviations for each run

Eight simulations were run (three factors at two levels). Each simulation is run for 500 hours, with the first 14 hours truncated in order to eliminate initialization effects (the first 14 error values are related to the warm-up period and are relatively small compared to others). The mean square deviation-which is the squared of each simulation's average medication delivery error minus the hospital's average medication delivery error-is calculated in Table 1. The experimental design was created using the Design-Expert Software. From the contrast constants for the $2^{3}$ design, the seven factorial effects and the sum of squares are estimated and shown in Table 2.

\begin{tabular}{|c|r|r|r|}
\hline Model Term & Effect Estimate & Sum of Squares & Percent Contribution \\
\hline$A$ & -0.0003275 & $2.14513 \mathrm{E}-07$ & 0.079326222 \\
\hline$B$ & -0.0104885 & 0.000220017 & 81.36187151 \\
\hline C & 0.0004825 & $4.65613 \mathrm{E}-07$ & 0.172182417 \\
\hline$A B$ & 0.0028080 & $1.57697 \mathrm{E}-05$ & 5.831608652 \\
\hline$A C$ & -0.0003030 & $1.83618 \mathrm{E}-07$ & 0.067901508 \\
\hline$B C$ & -0.0041070 & $3.37349 \mathrm{E}-05$ & 12.47508664 \\
\hline$A B C$ & -0.0001275 & $3.25125 \mathrm{E}-08$ & 0.012023047 \\
\hline
\end{tabular}

Table 2. Factor effect estimates and sums of squares

The half-normal probability plot of these effects is shown in Figure 6. All the effects that lie along the line are negligible, whereas the large effects are far from the line. The significant effects based on this analysis are the main effect of $B$ and the $B C$ and $A B$ interactions.

The mean square deviation is minimal with the following values for the three parameters:

- Pharmacist Reference Experience Level $=4000$ hours 
- Reference Error= $1 \mathrm{IV} /$ Hour

- Reference Workload= $30 \mathrm{IV} /$ Hour

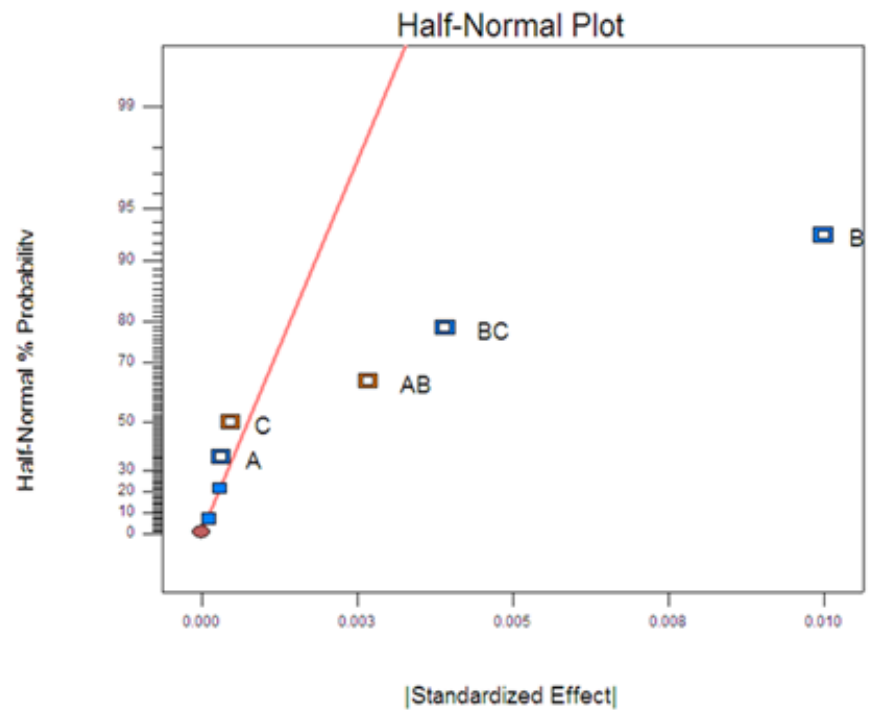

Figure 6. Half-normal probability plot of the medication delivery error effects (model validation)

The partial analysis of variance is summarized in Table 3. Based on the ANOVA, the main effect $B$ and the interactions of $A B$ and $B C$ (the effects with the P-Values less than 0.0500 ) are significant. If the interactions are not considered, the conclusion is that the reference error is the most significant factor.

\begin{tabular}{|c|r|r|r|r|r|}
\hline $\begin{array}{c}\text { Source of } \\
\text { Variation }\end{array}$ & $\begin{array}{c}\text { Sum of } \\
\text { Squares }\end{array}$ & $\begin{array}{c}\text { Degrees of } \\
\text { Freedom }\end{array}$ & Mean Square & F Value & P-Value \\
\hline A & $2.14513 \mathrm{E}-07$ & 1 & $2.14513 \mathrm{E}-07$ & 1.985028 & 0.2942 \\
\hline B & 0.000220017 & 1 & 0.000220017 & 2035.967 & 0.0005 \\
\hline C & $4.65613 \mathrm{E}-07$ & 1 & $4.65613 \mathrm{E}-07$ & 4.308624 & 0.1736 \\
\hline $\mathrm{AB}$ & $1.57697 \mathrm{E}-05$ & 1 & $1.57697 \mathrm{E}-05$ & 145.9278 & 0.0068 \\
\hline BC & $3.37349 \mathrm{E}-05$ & 1 & $3.37349 \mathrm{E}-05$ & 312.1716 & 0.0032 \\
\hline Error & $2.1613 \mathrm{E}-07$ & 2 & $1.08065 \mathrm{E}-07$ & & \\
\hline Total & 0.000270418 & 7 & & & \\
\hline
\end{tabular}

Table 3. Analysis of variance for the medication delivery error

After formulating the medication delivery error of the model, it is time to use an appropriate test to validate the model using medication delivery error data. Although the model's medication delivery error data hold a normal distribution assumption, the medication delivery error data of $\mathrm{CH}$ do not. Thus, classical $t$ tests cannot be used for model validation. Instead, nonparametric statistics methods are used. Nonparametric or distribution-free tests do not require the samples to be normal. However, they require assumptions for their validity, and these 
assumptions are less restrictive than the assumptions needed for the $t$ test (Navidi, 2008). For validation purposes the Mann-Whitney Test is used (Conover, 1999). Our samples meet all the assumptions of the test. The hypothesis test is:

$$
\begin{aligned}
& H_{0}: \mu_{\text {model }}=\mu_{\text {real }} \\
& H_{1}: \mu_{\text {model }} \neq \mu_{\text {real }}
\end{aligned}
$$

$X_{1}, X_{2} \ldots, X_{44}$ denote the random sample of size $n=44$ from the hospital data and $Y_{1}$, $Y_{2, \ldots,} Y_{44}$ denote the random sample of size $m=44$ from the model data. The ranks 1 to $n+m$ are assigned to the values from smallest to largest. $R\left(X_{i}\right)$ and $R\left(Y_{j}\right)$ denote the rank assigned to $X_{i}$ and $Y_{j}$ for all $i$ and $j$. In this case, none of the sample values are equal, so there is no tie in ranking. The test statistic is the sum of the ranks assigned to the sample from the real data:

$$
\mathrm{T}=\sum_{\mathrm{i}=1}^{44} \mathrm{R}(\mathrm{Xi})=1738
$$

$H_{0}$ will be rejected at the level of significance $a$ if $T$ is less than its $a / 2$ quantile or greater than its $(1-a / 2)$ quantile obtained from the following equation:

$$
w_{p} \cong \frac{n(n+m+1)}{2}+z_{p} \sqrt{\frac{n m(n+m+1)}{12}}
$$

$a$ is equal to 0.05 , so $z_{0.95}=1.6449$ and $w_{0.95}=2155.105 .(a / 2) w_{0.95}<T<(1-a / 2) w_{0.95}$.

So there is no sufficient evidence to reject HO. Therefore, the two means are statistically equal. The variances of the model medication delivery errors and the hospital medication delivery errors are also close to each other. Thus the model is validated.

\section{Simulation analysis}

The model has been simulated for 500 hours. We first analyze the medication delivery errors. Another important question is to check if the bullwhip effect (defined here, following Anderson et al. (2005), as the variance in the processing rate--and therefore the next stage's demand--being greater than the input task) occurs in the internal service supply chains of the hospital? We also analyze if the variance in each stage's backlog increases as one proceeds up the supply chain. 


\subsection{Medication delivery errors analysis and discussion}

It is clear that we always try to reduce the medication delivery error. Figure 7 shows the medication delivery error of the hospital in a normal situation.

To analyze the impact of the different parameters on the medication delivery errors, we use experimental design for the most important ones. Consider Table 4 for the parameters used in the experimental design.

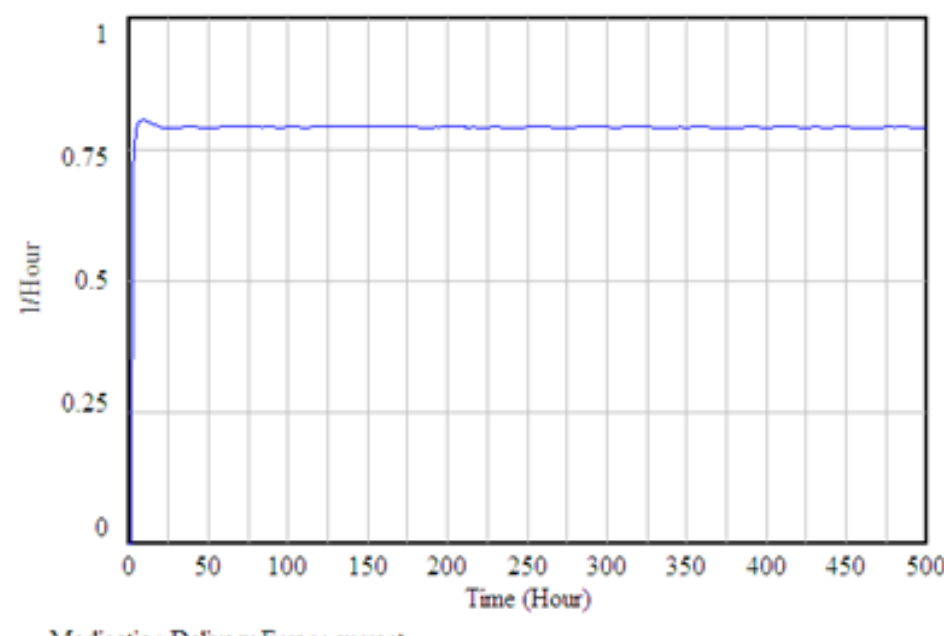

Medication Delivery Error : current

Figure 7. Medication Delivery Error

\begin{tabular}{|c|c|c|c|c|c|}
\hline \multicolumn{5}{|c|}{ Factor } & \multirow{6}{*}{$\begin{array}{l}\text { Average } \\
\text { Medication } \\
\text { Delivery } \\
\text { Error }\end{array}$} \\
\hline $\begin{array}{l}\text { Factor } \\
\text { Level }\end{array}$ & $\begin{array}{c}\text { New Hired } \\
\text { Pharmacist } \\
\text { Average } \\
\text { Experience }(A)\end{array}$ & $\begin{array}{l}\text { Pharmacist } \\
\text { Fractional } \\
\text { Attrition } \\
\text { Rate (B) }\end{array}$ & $\begin{array}{l}\text { Productivity of } \\
\text { Inexperienced } \\
\text { Pharmacist (C) }\end{array}$ & $\begin{array}{l}\text { Productivity of } \\
\text { Experienced } \\
\text { Pharmacist (D) }\end{array}$ & \\
\hline Units & Hours & Fraction & IV/Hour/Person & IV/Hour/Person & \\
\hline Low & 8000 & 0.02 & 1.2 & 3.1 & \\
\hline High & 24000 & 0.08 & 2.4 & 6.3 & \\
\hline Run & Factor A & Factor B & Factor C & Factor D & \\
\hline 1 & -1 & +1 & +1 & -1 & 0.79422 \\
\hline 2 & -1 & +1 & -1 & +1 & 0.79934 \\
\hline 3 & +1 & +1 & -1 & +1 & 0.79141 \\
\hline 4 & +1 & -1 & -1 & +1 & 0.76886 \\
\hline 5 & -1 & +1 & -1 & -1 & 0.78686 \\
\hline 6 & +1 & -1 & +1 & +1 & 0.76886 \\
\hline 7 & -1 & +1 & +1 & +1 & 0.81080 \\
\hline 8 & +1 & +1 & -1 & -1 & 0.77906 \\
\hline 9 & -1 & -1 & -1 & +1 & 0.77141 \\
\hline 10 & -1 & -1 & +1 & +1 & 0.78247 \\
\hline 11 & +1 & -1 & -1 & -1 & 0.75685 \\
\hline 12 & +1 & +1 & +1 & -1 & 0.78635 \\
\hline 13 & -1 & -1 & -1 & -1 & 0.78247 \\
\hline 14 & +1 & +1 & +1 & +1 & 0.78635 \\
\hline 15 & +1 & -1 & +1 & -1 & 0.76393 \\
\hline 16 & -1 & -1 & +1 & -1 & 0.75936 \\
\hline
\end{tabular}

Table 4. Values for the medication delivery error parameters in the experimental design and formation and results of the medication delivery error experimental design 
For the complete experimental design, we ran a total of 16 simulations (four factors at two levels). Table 4 contains each run formation and the average of the medication delivery error for each run. From the contrast constants for the $2^{4}$ design, the 15 factorial effects and the sum of squares are estimated and shown in Table 5. The half-normal probability plot of these effects is shown in Figure 8. All of the effects that lie along the line are negligible, whereas the large effects are far from the line. The significant effects based on this analysis are the main effects of $A, B, D$ and the $A C D$ interaction. The main effect $B$ is plotted in Figure 9. Based on the plot related to main effect $B$, the smaller the fractional attrition rate the smaller the medication delivery error would be. Thus, factor B should be chosen 0.02 . The optimal settings of the four parameters are:

- Pharmacist new hired average experience $=24000$ hours

- Pharmacist fractional attrition rate $=0.02$

- Productivity of inexperienced pharmacist= $1.2 \mathrm{IV} /$ hour $/$ person

- Productivity of experienced pharmacist=3.1 IV/hour/person

\begin{tabular}{|c|r|r|r|}
\hline Model Term & Effect Estimate & Sum of Squares & Percent Contribution \\
\hline$A$ & -0.0106575 & 0.000454329 & 13.62958821 \\
\hline$B$ & 0.0225225 & 0.002029052 & 60.87027213 \\
\hline C & 0.0020100 & $1.61604 \mathrm{E}-05$ & 0.484801737 \\
\hline$D$ & 0.0088000 & 0.00030976 & 9.292603276 \\
\hline$A B$ & -0.0013550 & $7.3441 \mathrm{E}-06$ & 0.220318336 \\
\hline$A C$ & 0.0003175 & $4.03225 \mathrm{E}-07$ & 0.012096494 \\
\hline$A D$ & -0.0014775 & $8.73202 \mathrm{E}-06$ & 0.261955204 \\
\hline BC & 0.0032525 & $4.2315 \mathrm{E}-05$ & 1.269423876 \\
\hline BD & 0.0015525 & $9.64103 \mathrm{E}-06$ & 0.289224627 \\
\hline CD & 0.0023550 & $2.21841 \mathrm{E}-05$ & 0.665508911 \\
\hline$A B C$ & -0.0044650 & $7.97449 \mathrm{E}-05$ & 2.392296355 \\
\hline$A B D$ & -0.0027000 & $2.916 \mathrm{E}-05$ & 0.874781481 \\
\hline$A C D$ & -0.0072125 & 0.000208081 & 6.242286601 \\
\hline$B C D$ & -0.0044175 & $7.80572 \mathrm{E}-05$ & 2.341667177 \\
\hline$A B C D$ & 0.0031000 & $3.844 \mathrm{E}-05$ & 1.153175587 \\
\hline
\end{tabular}

Table 5. Medication delivery error factor effect estimates and sums of squares

\begin{tabular}{|c|r|r|r|r|r|}
\hline $\begin{array}{c}\text { Source of } \\
\text { Variation }\end{array}$ & $\begin{array}{c}\text { Sum of } \\
\text { Squares }\end{array}$ & $\begin{array}{c}\text { Degrees of } \\
\text { Freedom }\end{array}$ & Mean Square & F Value & P-Value \\
\hline A & 0.000454329 & 1 & 0.000454329 & 11.17063281 & 0.0124 \\
\hline B & 0.002029052 & 1 & 0.002029052 & 49.88848148 & 0.0002 \\
\hline C & $1.61604 \mathrm{E}-05$ & 1 & $1.61604 \mathrm{E}-05$ & 0.397337183 & 0.5485 \\
\hline D & 0.00030976 & 1 & 0.00030976 & 7.616096499 & 0.0281 \\
\hline AC & $4.03225 \mathrm{E}-07$ & 1 & $4.03225 \mathrm{E}-07$ & 0.009914129 & 0.9235 \\
\hline AD & $8.73202 \mathrm{E}-06$ & 1 & $8.73202 \mathrm{E}-06$ & 0.21469507 & 0.6572 \\
\hline CD & $2.21841 \mathrm{E}-05$ & 1 & $2.21841 \mathrm{E}-05$ & 0.545442428 & 0.4842 \\
\hline ACD & 0.000208081 & 1 & 0.000208081 & 5.116096719 & 0.0582 \\
\hline Error & 0.000284702 & 7 & $4.06718 \mathrm{E}-05$ & & \\
\hline Total & 0.003333404 & 15 & & & \\
\hline
\end{tabular}

Table 6. Analysis of variance for the medication delivery error 


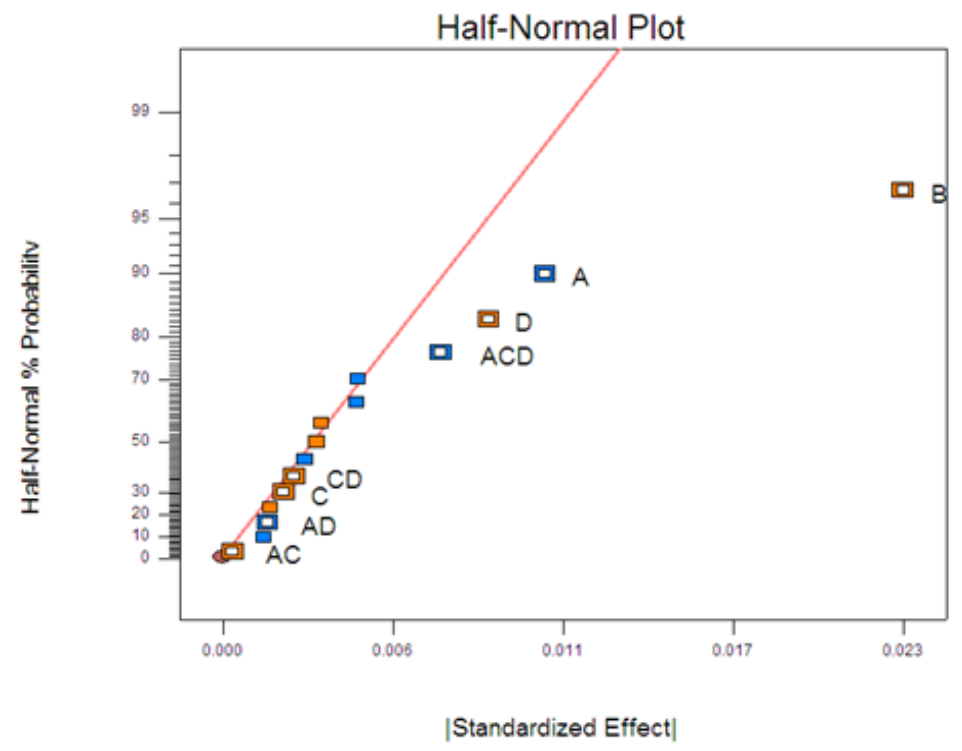

Figure 8. Half-normal probability plot of the medication delivery error effects

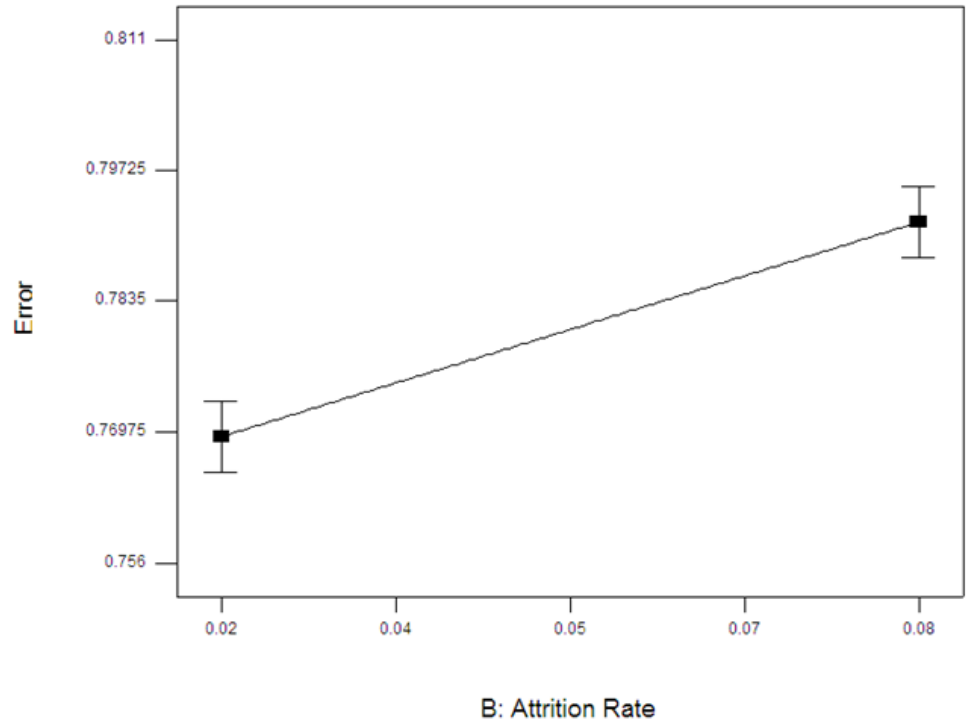

Figure 9. Main effect of the attrition rate versus medication delivery error plot

\subsection{Bullwhip effect analysis and discussion}

To check if the bullwhip effect occurs in the modelled service supply chains a pulse has been imposed to the patient demand at time 70 . The chosen duration of the pulse is 80 hours. The pulse is added to the minimum, maximum and mean values of the random normal distribution. Thus, the formula of the patient demand is now:

RANDOM NORMAL $(1+\operatorname{PULSE}(70,80), 5$ + PULSE $(70,80), 2.5+\operatorname{PULSE}(70,80)$, $0.5,0.5)$ 
To begin our analysis, consider Figure 10 which shows the patient demand as well as the processing rates for the four stages in ER. The phase lags, which show the delay from one stage to the next one, can be clearly seen. The same effect happens for the backlogs (see Figure 11). However, by looking at the variances of the processing rates and backlogs, the evidence for the bullwhip effect is unclear. We can justify this phenomenon using the four major root causes of the bullwhip effect proposed by Lee et al. (1997). The four root causes are demand signalling, order batching, price fluctuation, and rationing and shortage gaming. However, because of the intangible nature of the services and the fact that finished goods inventories cannot be used as a buffer against demand fluctuations, it is unlikely that demand signalling will be an important root cause of amplification effects in all the service supply chains. In the case of $\mathrm{CH}$, among the four stages of the $\mathrm{ER}$, there is no special room for demand forecasting. The same number of patients who enter the $E R$ and go through the registration will pass the other stages. Also, because of the intangibility of services, order batching cannot be a root cause of amplification effects in service operations. Price fluctuation may be a root cause of the bullwhip effect in some service supply chains. However, in this case it certainly cannot be a cause. People go to the ER when they are in a serious need. They cannot forward buy the ER services in the case of the price fluctuations. In fact, ER services are not offered at discount prices to attract customers in anticipation of periods of reduced demand. Service operations offer no obvious examples of shortage gaming, but when buying certain services customers, may apply rationing practices. However, because of the unpredictable nature of the need for ER services, this is not true for the ER. Thus, none of the four root causes of the bullwhip effect can be a cause for the ER services. Furthermore, there is a good level of communication between all the stages in ER. The four stages almost face the same level of fluctuations.

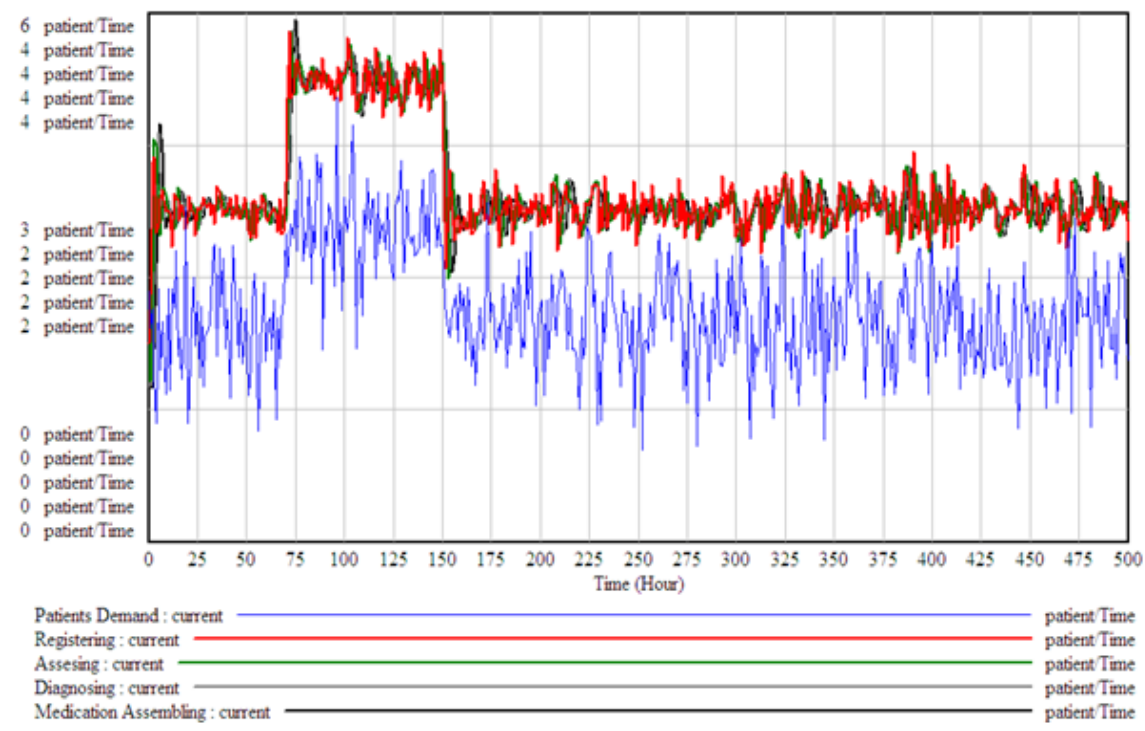


Figure 10. ER's demand and processing rates

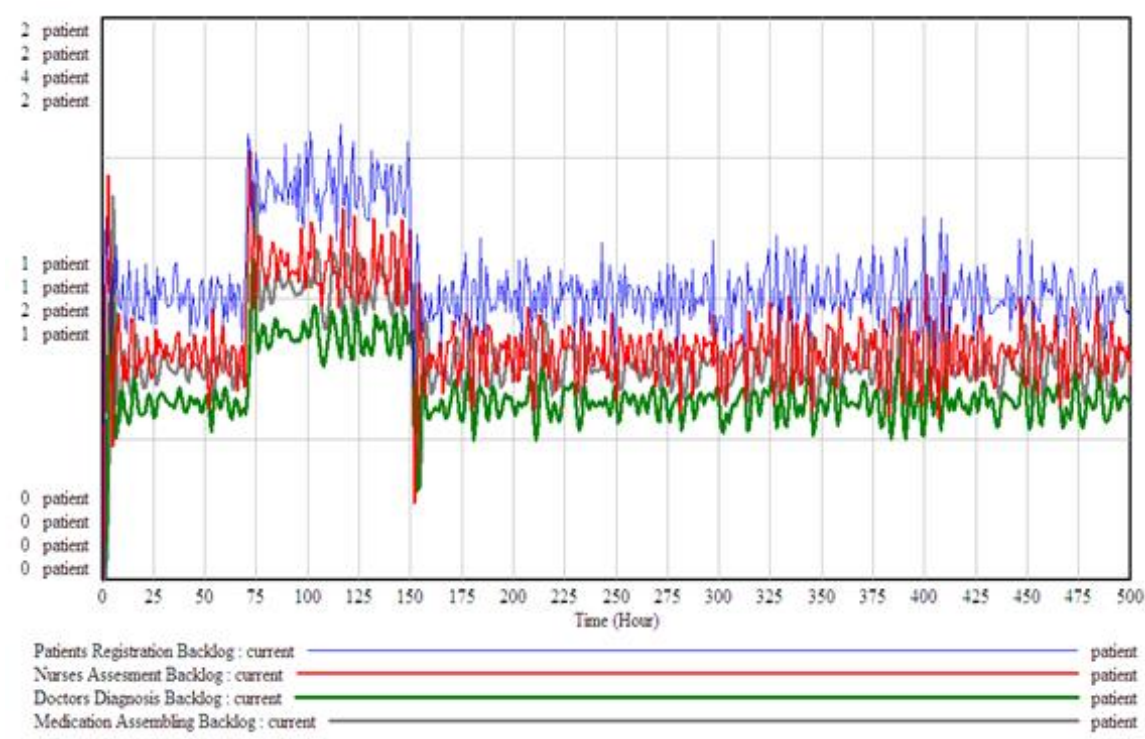

Figure 11. ER's backlogs

The same results are true for the pharmacy processing rates and backlogs (see Figures 12 and 13). However, it should be noted that the type of service supply chains modelled in this paper, are internal service supply chains, representing only the tasks which are done inside the pharmacy and the ER of a hospital. To observe the bullwhip effect in a healthcare service supply chains, one should consider and study the whole supply chain from downstream to upstream. For example, the service supply chain may involve the hospital as one stage along with the insurance company and other related firms as other stages.

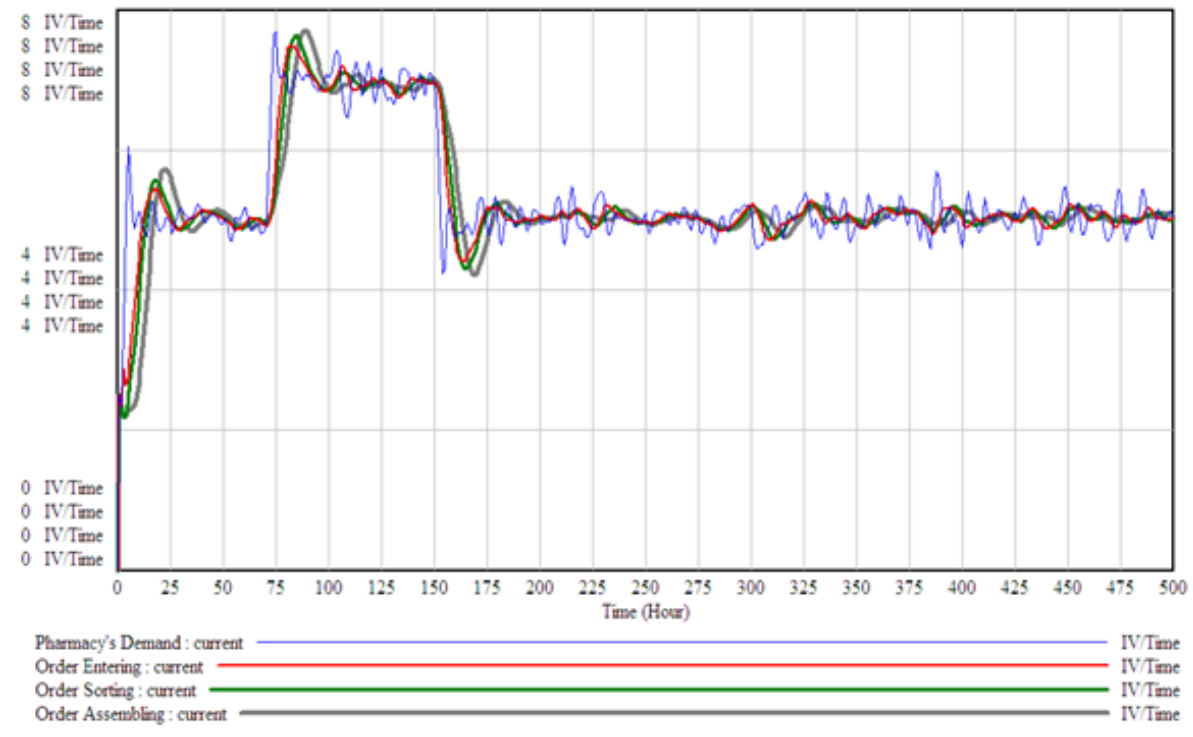

Figure 12. Pharmacy's demand and processing rates 


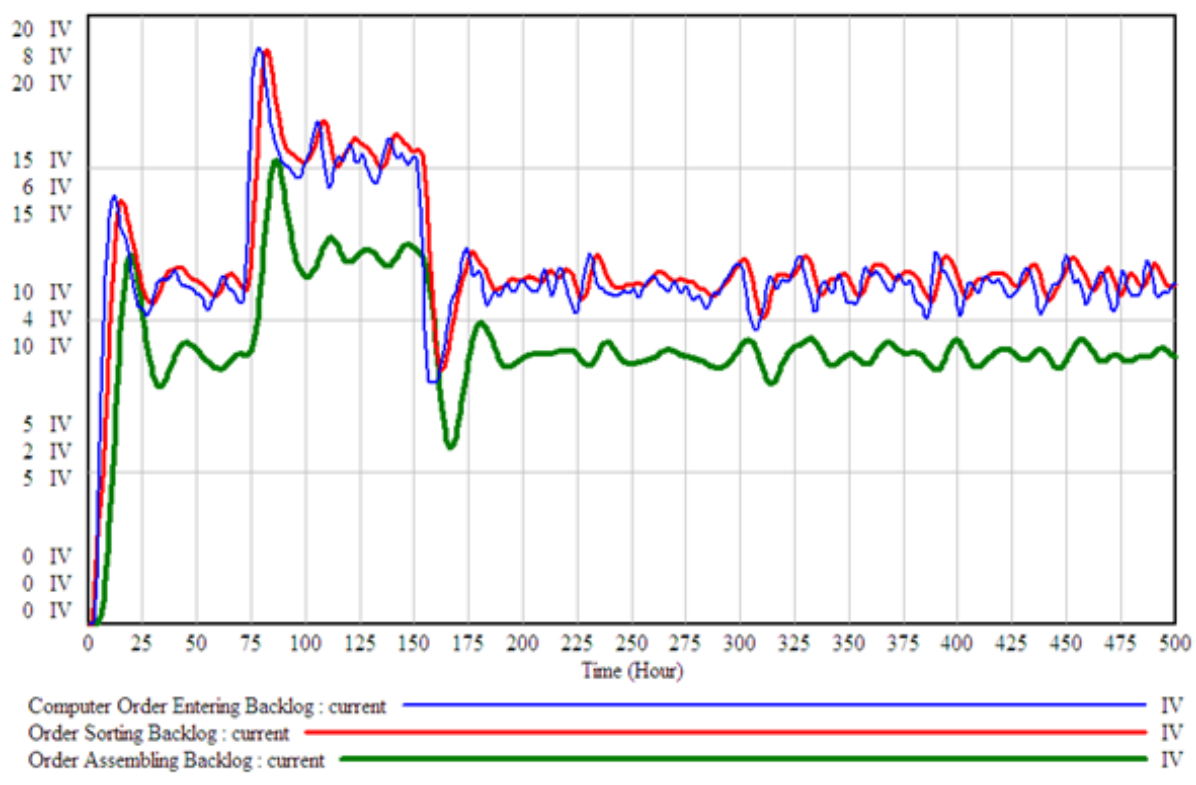

Figure 13. Pharmacy's backlogs

\section{Conclusions}

This paper models and simulates the processes of two internal service supply chains of a hospital to study the effects of different input parameters on the outputs and capability measures of the processes. This study can help the hospital improve processes, reduce errors, and deliver more efficient services. The paper focuses on medication delivery errors and amplification effects of demand.

According to the results of this study, the following managerial policies are suggested to reduce medication delivery errors of the hospital:

- Hiring employees with more average experiences can reduce medication delivery errors.

- Decreasing the fractional attrition rate, which means having more experienced employees for a longer time in the pharmacy, can reduce medication delivery errors.

- There is a trade-off between the productivity of the employees and medication delivery errors. Increasing the productivity could increase the errors. The task of assembling the medications needs accuracy. Therefore, the manager should try not to allow the productivity to increase more than a certain level. 
Another result from this study is that the bullwhip effect may not occur in a hospital's pharmacy and ER service supply chains. It should be noted that the type of service supply chains modelled in this paper are internal service supply chains, representing only the tasks which are done inside the pharmacy and the ER of a hospital. To observe the bullwhip effect, one should consider and study the whole supply chain from downstream to upstream because the bullwhip effect indicates that variations are amplified as one moves from downstream to upstream in the supply chain. Therefore the chains should be modelled more generally to observe the bullwhip effect in healthcare service supply chains. For example, the service supply chain may involve the hospital as one stage along with the insurance company and other related firms as other stages. In this case the bullwhip effect may be observed. It is observed that the four root causes mentioned by Lee et al. (1997) are not valid in the case of the pharmacy and ER service supply chains. Another reason that the bullwhip effect does not occur is the good level of communication between the stages in the pharmacy and ER service supply chains.

\section{Future research}

As noted before, the type of service supply chains modelled in this paper, are small service supply chains, representing only the tasks which are done inside the pharmacy and the ER of a hospital. To better observe the bullwhip effect in healthcare service supply chains, the chains should be modelled more generally. Thus modelling the hospital as a stage in healthcare service supply chains along with the insurance company and other related firms is recommended. Also analyzing the relationships between medication delivery errors and variability of backlogs and capacities is a good direction for future research. The impact of medication delivery errors on bullwhip effect is not considered in this paper. Modelling hospital's service supply chain in a way to show the relationships between medication delivery errors and the backlog and capacity variations is recommended.

\section{References}

Akkermans, H.A., \& Vos, B. (2003). Amplification in service supply chains: An exploratory case study from the telecom industry. Production and Operations Management, 12(2), 204-223. http://dx.doi.org/10.1111/j.1937-5956.2003.tb00501.x 
Anderson, E.G., Morrice, D.J., \& Lundeen, G. (2005). The "physics" of capacity and backlog management in service and custom manufacturing supply chains. System Dynamics Review, 21(3), 217-247. http://dx.doi.org/10.1002/sdr.319

Baker, K.N, Flynn, E.A., \& Pepper, G.A., Bates, M.D., \& Mikeal, R.L. (2002). Medication errors observed in 36 health care facilities, Arch Intern Med, 162, 1897-1903. http://dx.doi.org/10.1001/archinte.162.16.1897

Baltacioglu T., Ada E., Kaplan M., Yurt O., \& Kaplan C. (2007). A New Framework for Service Supply Chains. Services industry journal, 27(2), 105-124.

Berry, L., \& Bendapudi, N. (2007). Health care: A fertile field for service research. Journal of Service Research, 10(2), 111-122. http://dx.doi.org/10.1177/1094670507306682

Bier, F.J. (1995). The management of the supply chain for hospital pharmacies: a focus on inventory management. Journal of Business Logistics, 16(2), 153-173.

Conover, W.J. (1999). Practical nonparametric statistics (3 $3^{\text {rd }}$ Ed.). John Wiley \& Sons.

Fineman, S.J., \& Kapadia, A.S. (1978). An Analysis of the Logistics of Supplying and Processing Sterilized Items in Hospitals. Computers and Operation Research, 5, 47-54. http://dx.doi.org/10.1016/0305-0548(78)90017-5

Forrester, J.W. (1961). Industrial dynamics. Cambridge: MA.

Kaushal, R., Bates, D., Landrigan, C., McKenna, K.J., Clapp, M.D., Federico, F. \& Goldmann, D.A. (2001). Medication errors and adverse drug events in pediatric inpatients. JAMA, 285, 2114-2120. http://dx.doi.org/10.1001/jama.285.16.2114

Lee, H.L., Padmanabhan, P., \& Whang, S. (1997). Information distortion in a supply chain: the bullwhip effect. Management Science, 43(4), 516-558. http://dx.doi.org/10.1287/mnsc.43.4.546

Lee, H.L., Padmanabhan, V., \& Whang, S. (1997). The bullwhip effect in supply chains. Sloan Management Review, 38(3), 93-102.

Navidi, W.C. (2007). Statistics for Engineers. McGraw-Hill.

Rivard-Royer, H., Landry, S., \& Beaulieu, M. (2002). Hybrid stockless: A case study: Lessons for health-care supply chain integration. International Journal of 
Operations \& Production Management, 22(4), 414-424. http://dx.doi.org/10.1108/01443570210420412

Ross L., Wallace, J., \& Paton, J. (2000). Medication errors in a pediatric teaching hospital in the UK: Five years operational experience. Arch Dis Child, 83, 492497. http://dx.doi.org/10.1136/adc.83.6.492

Sterman, J.D. (2000). Business dynamics: Systems thinking and modeling for a Complex World. Irwine/McGraw-Hill, Boston: MA.

Sterman, J.D. (1989a). Misperceptions of feedback in dynamic decision making. Organizational Behavior and Human Decision Processes, 43(3), 301-335. http://dx.doi.org/10.1016/0749-5978(89)90041-1

Sterman, J.D. (1989b). Modeling management behavior: Misperceptions of feedback in a dynamic decision making experiment. Management Science, 35(3), 321-339. http://dx.doi.org/10.1287/mnsc.35.3.321

Vanerveen, T. (2005). Averting highest-risk errors is first priority. Patient Safety and Quality Healthcare, 2, 16-21.

Williams, C., \& Maddox, R. (2005). Implementation of an IV medication safety system. Am J Health-Syst Pharm, 62, 530-536.

Zangwill, W.I., \& Kantor, P.B. (1998). Toward a Theory of Continuous Improvement and the Learning Curve. Management Science, 44(7), 910-920. http://dx.doi.org/10.1287/mnsc.44.7.910

Zeithaml, V.A., Bitner, M.J., \& Gremler, D.D. (2009). Services marketing: Integrating customer focus across the firm (5 $5^{\text {th }}$ Edition). McGraw-Hill Higher Education.

Journal of Industrial Engineering and Management, 2011 (www.jiem.org)

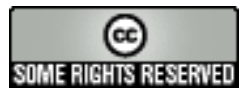

\footnotetext{
Article's contents are provided on a Attribution-Non Commercial 3.0 Creative commons license. Readers are allowed to copy, distribute and communicate article's contents, provided the author's and Journal of Industrial Engineering and Management's names are included. It must not be used for commercial purposes. To see the complete license contents, please visit http://creativecommons.org/licenses/by-nc/3.0/.
} 